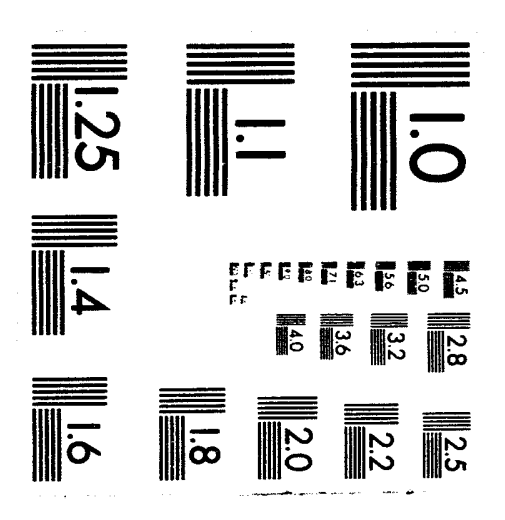



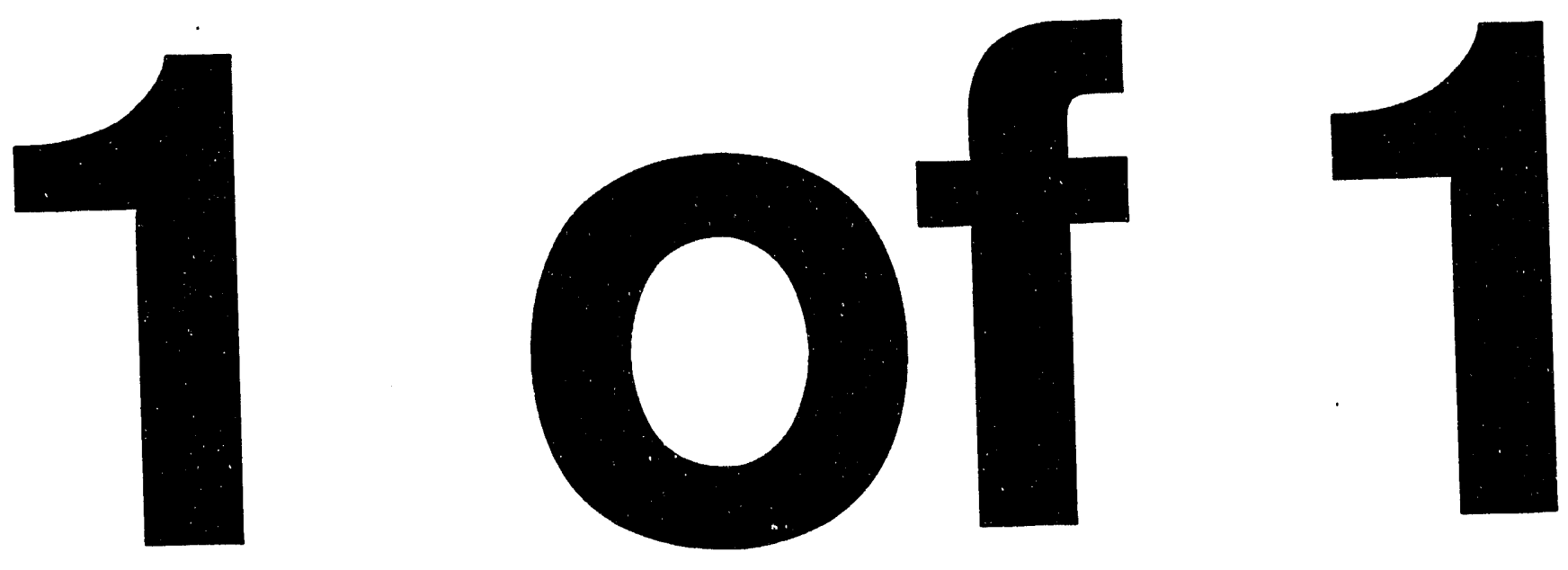
LA-UR- $94-789$

Title:

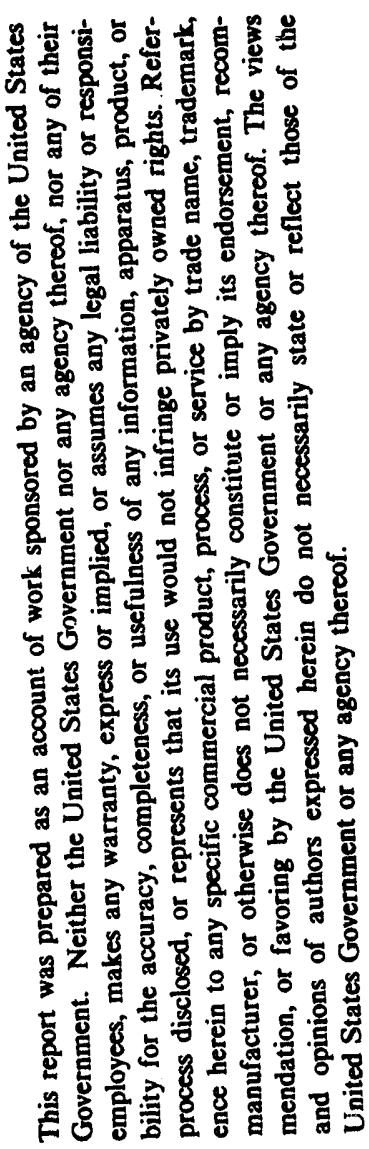

Submitted to:
Evaluation of Oxygen Interactions with Materials III Mission and Induced Environments

Steven L. Koontz, Lubert J. Leger, Steven L. Rickman, Jon B. Cross, Charles L. Hakes, and David T. Bu1

LDEF Symposium, NASA/Langley, November 8-12, 1993 Willaimsburg, VA, Published as NASA Proceedings; Journal of Space Craft and Rockets

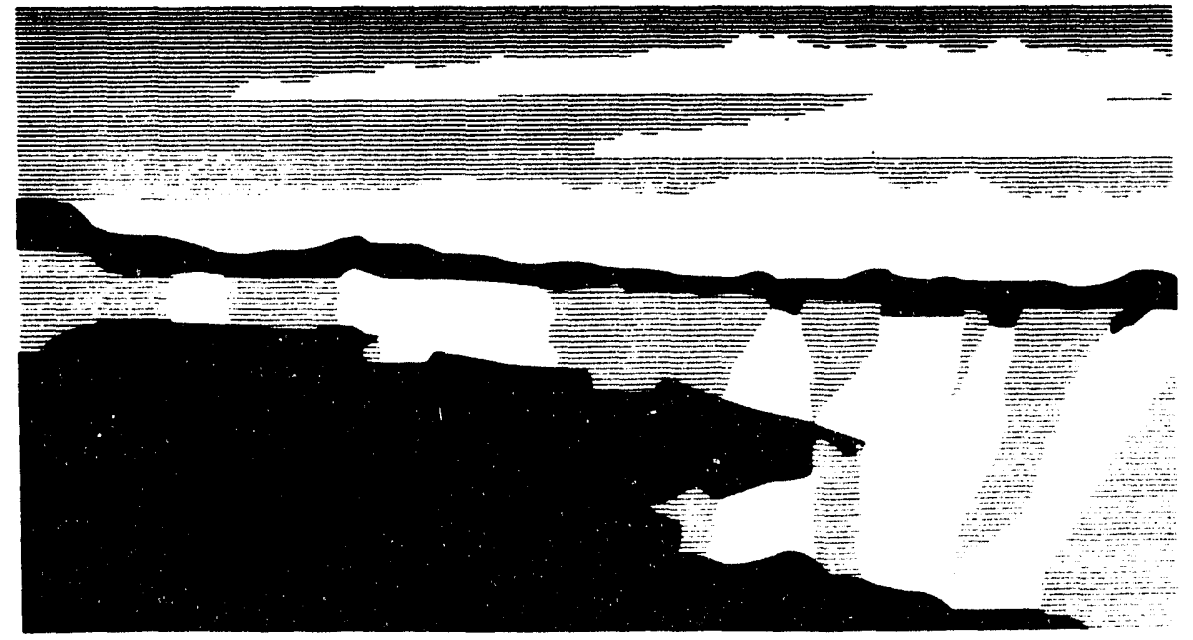

Los Alamos National Laboralory, an affirmative action/equal opportunity employer, is operated by the University of California for the U.S. Department of Energy under contract W-7405-ENG-36. By acceptance of this article, the publisher recognizes that the U.S. Government retains a nonexclusive, royalty-free license to publish or reproduce the published form of this contribution, or to allow others to do so, for U.S. Government purposes. The Los Alamos National Laboratory requests that the publisher identify this anticie as work performed under the auspices of the U.S. Department of Energy. 


\title{
EVALUATION OF OXYGEN INTERACTIONS WITH MATERLALS III - MISSION AND INDUCED ENVIRONMENTS
}

\author{
Steven L. Koontz, Lubert J. Leger, Steven L. Rickman \\ NASA Lyndon B. Johnson Space Center \\ Houston, TX 77058
}

Phone: 713/483-5906, Fax: 713/483-2162

\author{
Jon B. Cross \\ Los Alamos National Laboratory \\ Los Alamos, NM \\ Phone: 505/667-0511, Fax: 505/665-4631 \\ Charles L. Hakes, David T. Bui \\ Lockheed Engineering \& Sciences Company \\ Houston, Texas 77058 \\ Phone: 713/333-7804, Fax: 713/333-7727
}

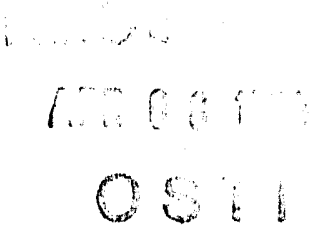

\begin{abstract}
The Evaluation of Oxygen Interactions with Materials III (EOIM-III) flight experiment $u d s$ developed to obtain benchmark atomic oxygen/material reactivity data. The experiment was conducted during Space Shuttle mission 46 (STS-46), which flew July 31 to August 7, 1992. Quantitative interpretation of the materials reactivity measurements requires a complete and accurate detinition of the space environment exposure, including the thermal history of the payload, the solar ultraviolet exposure. and the atomic oxygen fluence. The thermal history of the payload was measured using twelve thermocouple sensors placed behind selected samples and on the EOIM-III payload structure. The solar ultraviolet exposure history of the EOIM-III payload was determined by analysis of the as-tlown orbit and vehicle attitude combined with daily average solar ultraviolet and vacuum ultraviolet (UV/VLV) fluxes. The atomic oxygen fluence was assessed in three different ways. First, the O-atom tluence was calculated using a program that incorporates the MSIS-86 atmospheric model, the as-flown Space Shuttle trajectory, and solar activity parameters. Second, the oxygen atom fluence was estimated directly from Kapton film erosion. Third, ambient oxygen atom measurements were made using the quadrupole mass spectrometer on the EOIM-III payload. Our best estimate of the oxygen atom fluence as of this writing is $2.3 \pm 0.3 \times 10^{20}$ atoms per square centimeter. Finally, results of post-flight $X$-ray photoelectron spectroscopy (XPS) surface analyses of selected samples indicate low levels of contamination on the payload surface.
\end{abstract}

\section{INTRODUCTION}

Previous studies(ref. 1) of atomic oxygen reactivity with materials used on low-Earth-orbiting spacecraft have been based on material changes measured in the laboratory and normalized to atomic oxygen fluence as derived from spacecraft flight conditions and ambient density predictions (MSIS-86).(ref. 2,3) Some questions regarding the validity of using long-term-based ambient density models for short-term flight experiments have arisen. (ref. 4,5) In an attempt to resolve this uncertainty, the Evaluation of Oxygen Interactions with Materials III (EOIM-III) flight experiment was conducted on Space Shuttle mission 46 (STS-46), which flew July 31 to August 7, 1992. This paper presents a detailed description of the space environment exposure for STS-46 and the EOIM-III flight experiment. An overview of the EOIM-III flight measurements and supporting ground measurements are included in reference 6 . 


\section{FLIGHT SUMMARY}

The STS-46 mission altitudes and attitudes were scheduled to accommodate three primary payloads, of which the EOIM-III was sequentially the third and final. The orbital inclination was 28.5 degrees and the solar beta ang.e (the angle between the orbit plane and the Earth-Sun vector) varied between 17.5 and 24.3 degrees. The STS-46 altitudes as a function of Mission Elapsed Time (MET) are shown in figure 1. The highest $(430 \mathrm{~km})$ orbit, occurring from MET 0-70 hours, was flown to support the release of the European Retrievable Carrier (EURECA) satellite. The second $(300 \mathrm{~km})$ orbit, occurring from MET 70-140 hours, was for Tethered Satellite System (TSS) operations. The lowest $(230 \mathrm{~km})$ orbit supported the EOIM-III experiment, exposing the orbiter and all payloads to a far denser atmosphere than the earlier, higher, orbits. The molecular density of the atmosphere at the EOIM-III altitude was approximately 10 times higher than the density at the TSS-deploy altitude, and approximately $1(x)$ times higher than the EURECA-release altitude. Because of the density increase at low altitudes and the nonram orientations flown during most of the rest of the tlight, approximately 95 percent of the total atomic oxygen tluence occurred during the EOIM-III portion of the mission.

The environmental exposure of the EOIM-III payload also depended on the attitude of the orbiter with respect to the direction of flight (ram direction), and with respect to the Sun. The attitude timeline in figure 2 shows the angle between the cargo bay normal ( $-Z$ in orbiter body coordinates) and the orbiter velocity vector. The angle shown in figure 2 runs from 0 degrees, corresponding to the - ZVV or ram orientation, to 180 degrees, corresponding to ZVV or anti-ram (heat shield into the velocity vector). The oscillations between 0 and 180 degrees visible during earlier parts of the mission correspond to inertial hold attitudes or roll maneuvers. The EURECA-release portion of the thight included periods of ram attitude and periods of a solar inertial hold, during which time the cargo bay was facing the Sun. The EOIM-III mass spectrometer was on for approximately 17 hours during this part of the flight. The TSS-deploy portion of the flight comprised mostly an "airplane mode" orientation, where the cargo bay: was facing away from Earth. The mass spectrometer was on for about 4 hours during TSS operations.

\section{THERMAL HISTORY}

The thermal history of the EOIM-III payload was measured by 11 thermocouple sensors placed behind selected samples and on the EOIM-III payload structure, as shown in figure 3. Because of noise in the temperature data, and the large number of measurements from each sensor (one sample per second), the data were appropriately filtered and time-averaged before plotting. Figures 4.1 through 4.11 show the filtered output of the sensors. Temperature variations are consistent with vehicle tlight conditions, with the hottest period for the passive plates occurring during the EURECA-release portion of the flight. Diumal variations in temperature are visible in the data (note MET 100-130 hours on the

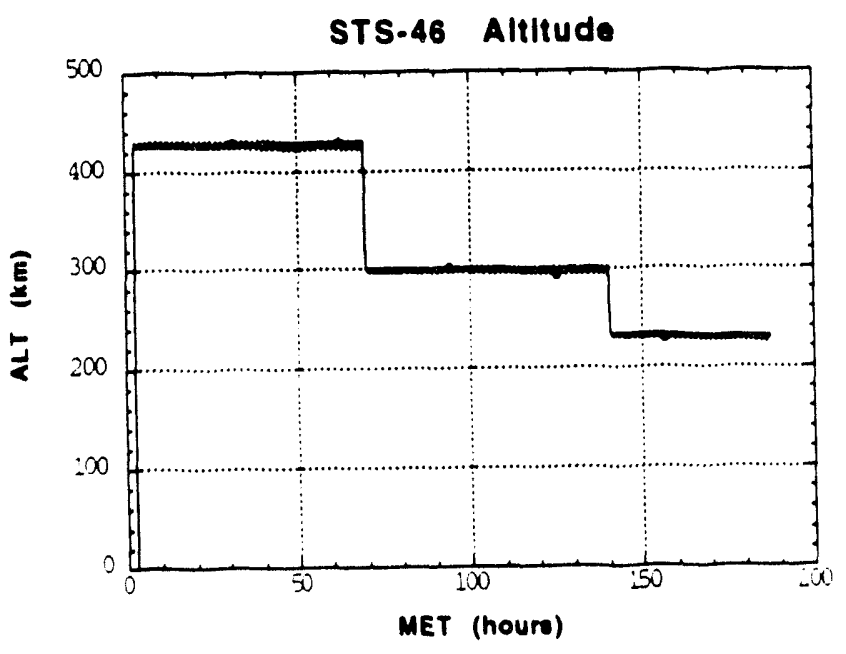

Figure 1 - STS -46 mission altitude timeline.

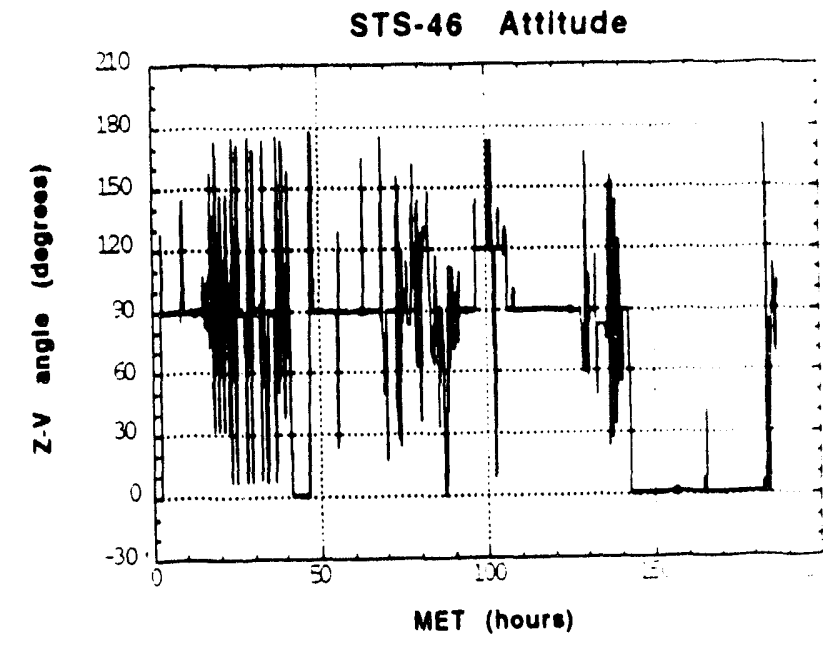

Figure 2 - STS.46 mission attitude timeline. 


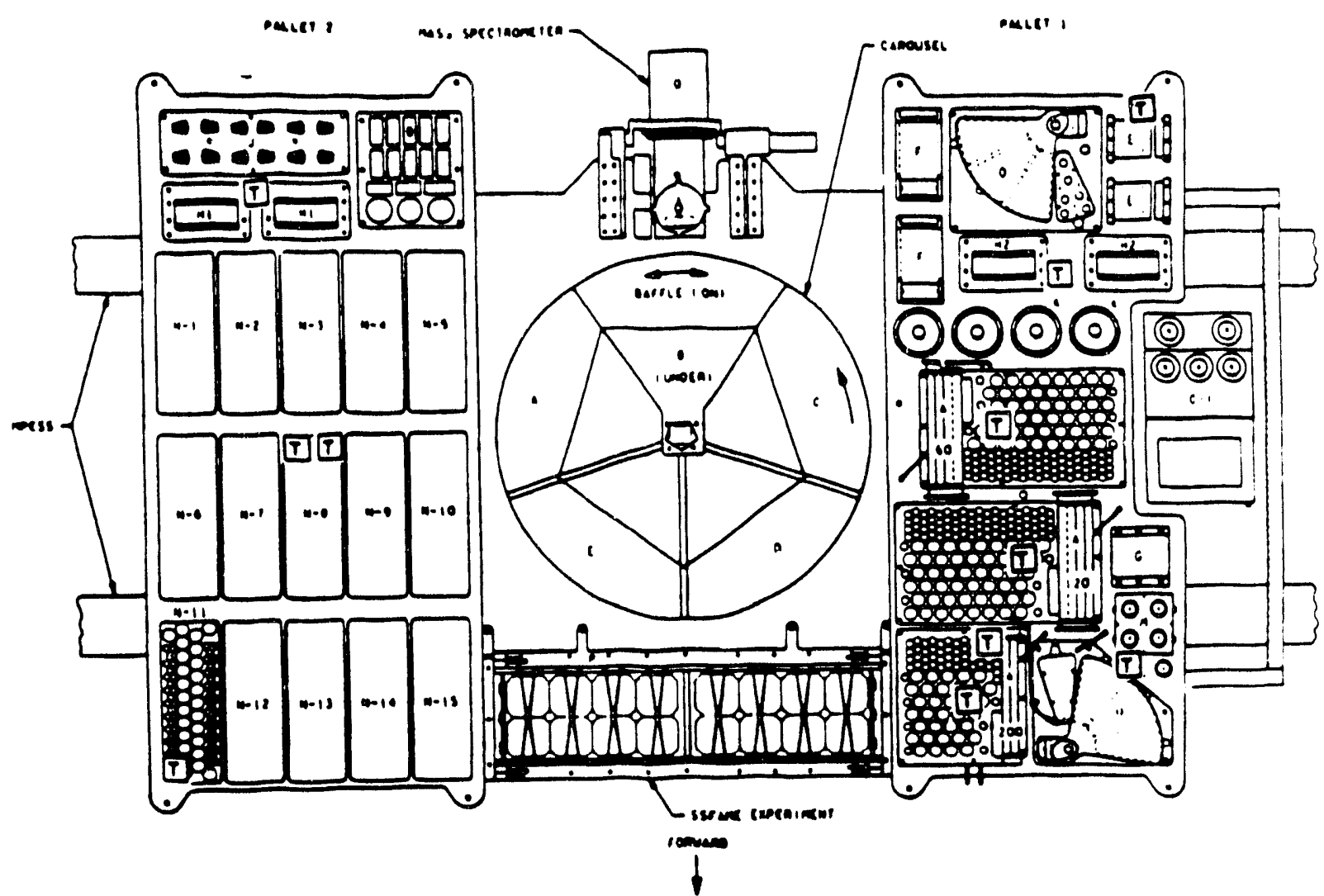

Figure 3 - EOIM-III Temperature sensor locations (marked with boxed T).

figures). Other temperature variations are due to vehicle attitude or operations of heaters on the temperature-controlled plates.

The thermal mass, thermal conductivity and thermo-optical properties of the thermocouple muunting assembly determine the temperature reported by the thermocouple sensor. This temperature is unly an approximation of the temperature of any nearby materials samples. The effects of sample thermooptical property variations can be gauged by a comparison of the two thermocouple readings from the

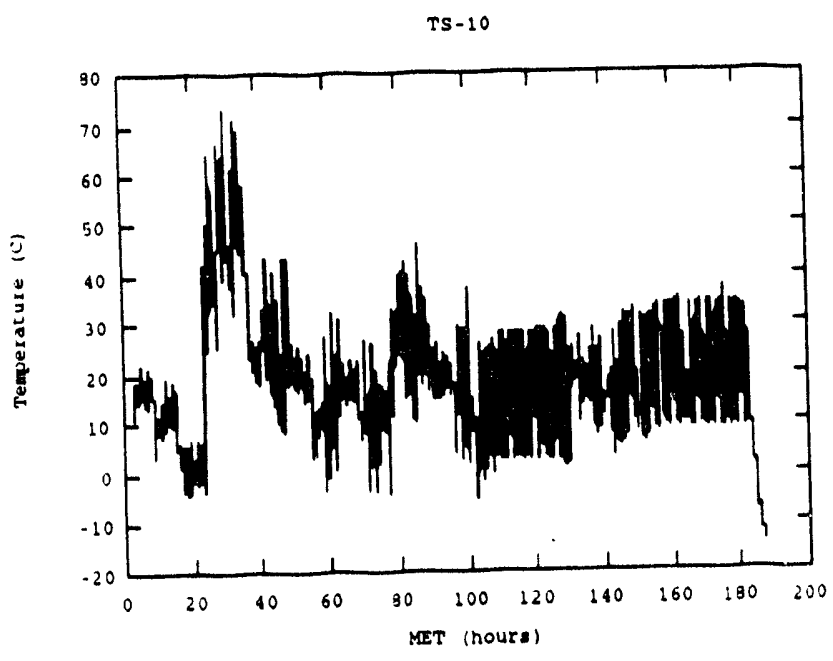

Figure 4.1 - Temperature recorded by the sensor on the Pallet 2 Sample Disk/Carrier N-8. The temperature sensor was mounted under aluminized Kapton tilm with the Kapton side up.

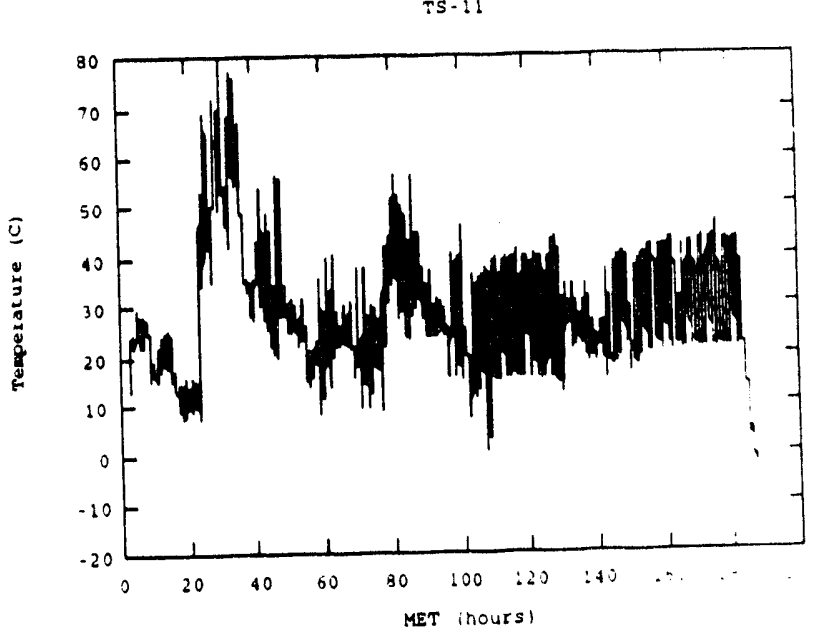

Figure 4.2 - Temperature recorded by the sensor on the Pallet 2 Sample Disk/Carrier N-8. The temperature sensor was mounted under aluminized Kapton tilm wilh the Aluminum side up. 
$T S \cdot 12$

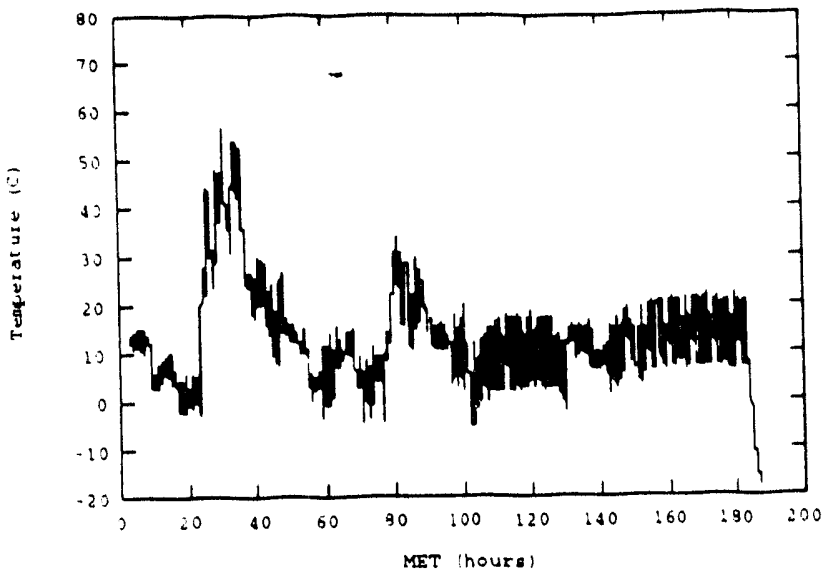

Figure 4.3 - Temperature recorded by the sensor on the Pallet 2 Sample Carrier N-11. :s. is

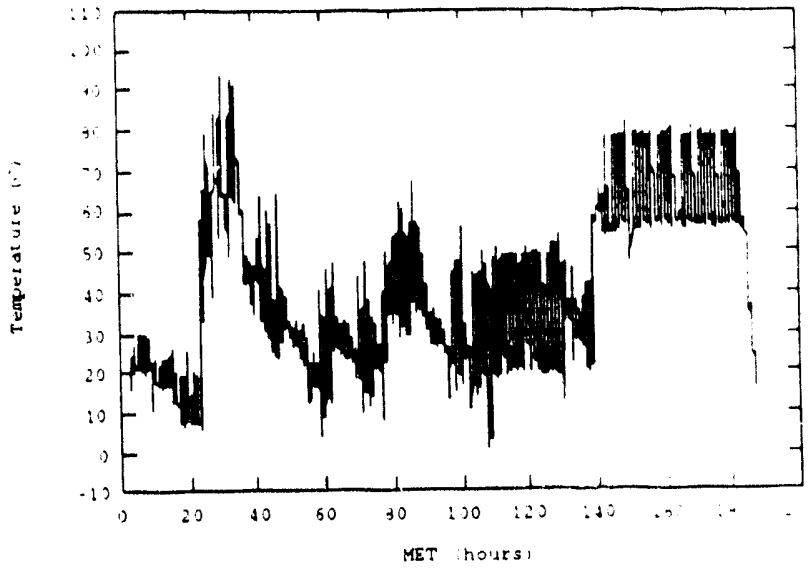

Figure 4.4 - Temperature recorded by the sensor on the Pallet $1\left(60^{\circ} \mathrm{C}\right)$ heated plate at the sample disk.

Pallet 2 Sample Disk Carrier Number 8 sample cells, shown if figures 4.1 and 4.2. The physical configuration of the two thermocouple sensors were identical, except for sample thermo-optical properties, and the sensor assemblies were adjacent to each other on the sample carrier (adjacent sample cells). Thermo-optical properties were determined by the choice of sample material mounted on top of each sensor; aluminized Kapton film with the aluminum side up in one case $(\alpha=0.12, \varepsilon=0 .() 1, \alpha / \varepsilon=3)$ and the Kapton side up in the other $(\alpha=0.33, \varepsilon=0.82, \alpha / \varepsilon=0.4)$. The effect of the rather large change in $\alpha / \varepsilon$ can be seen in figures 4.1 and 4.2 , where the aluminum-side-up shows significantly higher temperatures throughout the mission. During the 42 hour EOIM-III period, the average temperatures were 30.6 degrees Centigrade and 20.0 degrees Centigrade for the aluminum-side-up sensor and the Kapton-side-up sensor respectively. The extremes of temperature resulting from diumal variations in solar heating were from 16.5 to 47.0 degrees Centigrade for the aluminum-side-up sensor and from 5.3 to 36.9 degrees Centigrade for the Kapton-side-up sensor.

Thermocouple sensors on the 200 degree heated tray were placed both on the tray thermostat and in a sample holder cell. The thermo-optical properties for the sample cell sensor were determined by an anodized aluminum disk that was identical to the rest of the payload aluminum, so that any differences between the sensor readings were due to configuration interactions alone. As shown in figures 4.6 and 4.7 , the thermostat sensor on the 200 degree tray shows a much smaller diurnal temperature variation and a significantly higher mean temperature than the sample cell sensor. The mean, maximum, and minimum temperatures during the EOIM-III exposure (excluding the large temperature drop that

TS - 04

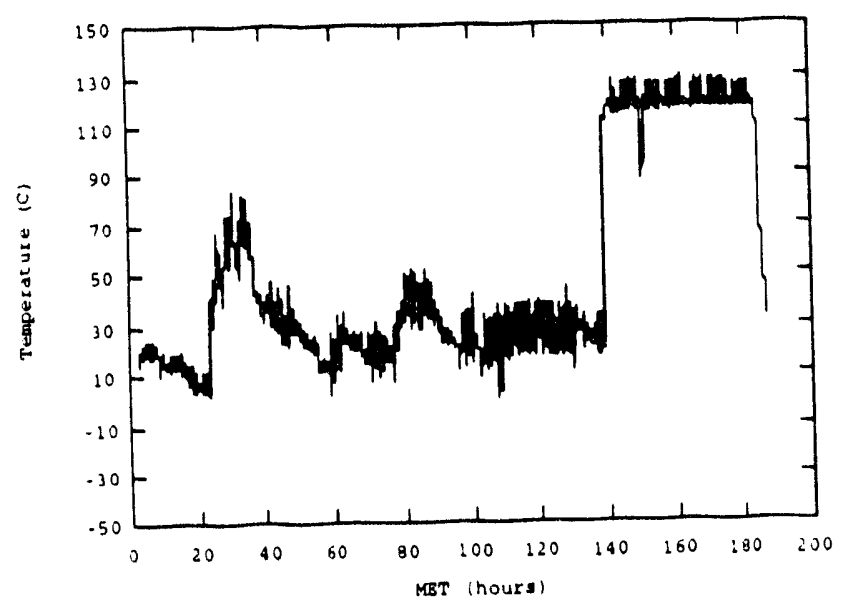

Figure 4.5 - Temperature recorded by the sensor on the Pallet $1\left(120^{\circ} \mathrm{C}\right)$ beated plate at the sample disk.
Ts-07

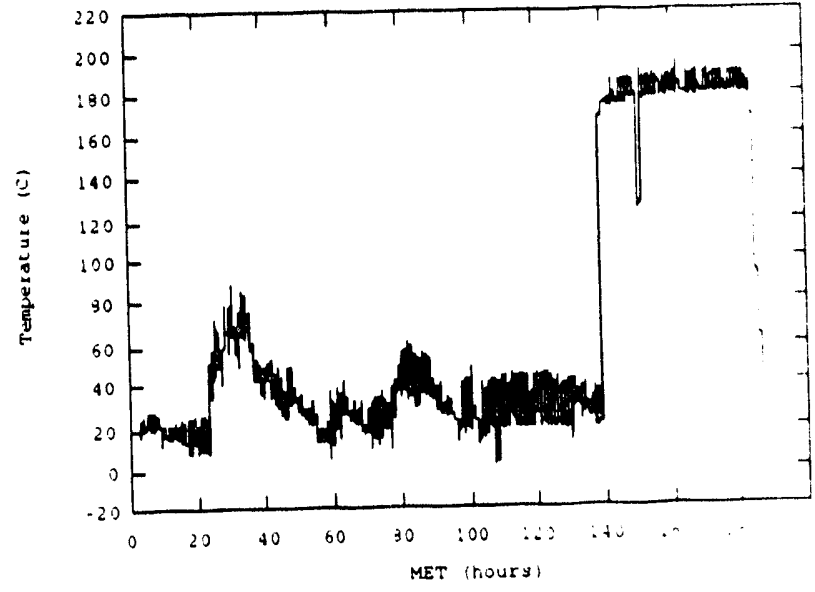

Figure 4.6 - Temperature recorded by the sensor on the Pallet $1\left(200^{\circ} \mathrm{C}\right)$ heated plate at the sample disk. 
TS.05

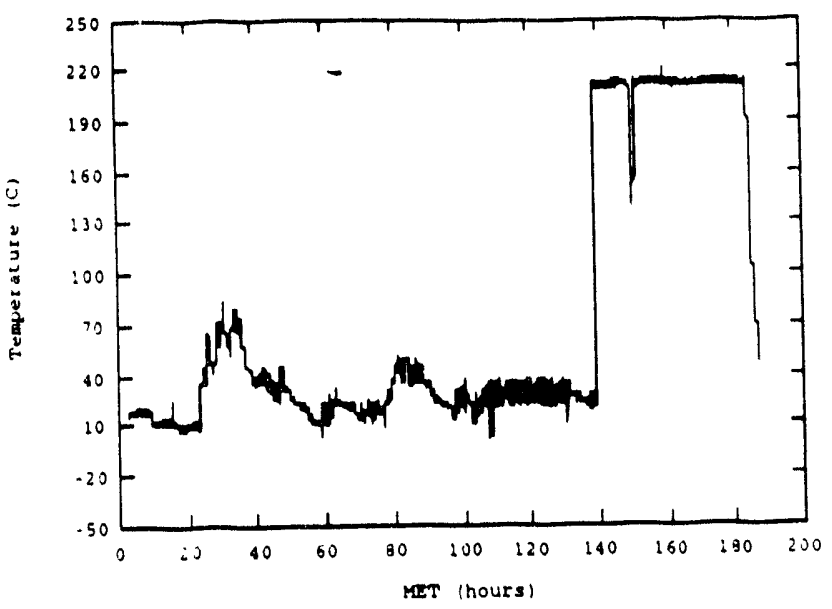

Figure 4.7 - Temperature recorded by the sensor on the Pallet $1\left(200^{\circ} \mathrm{C}\right)$ beated plate at the thermostat.

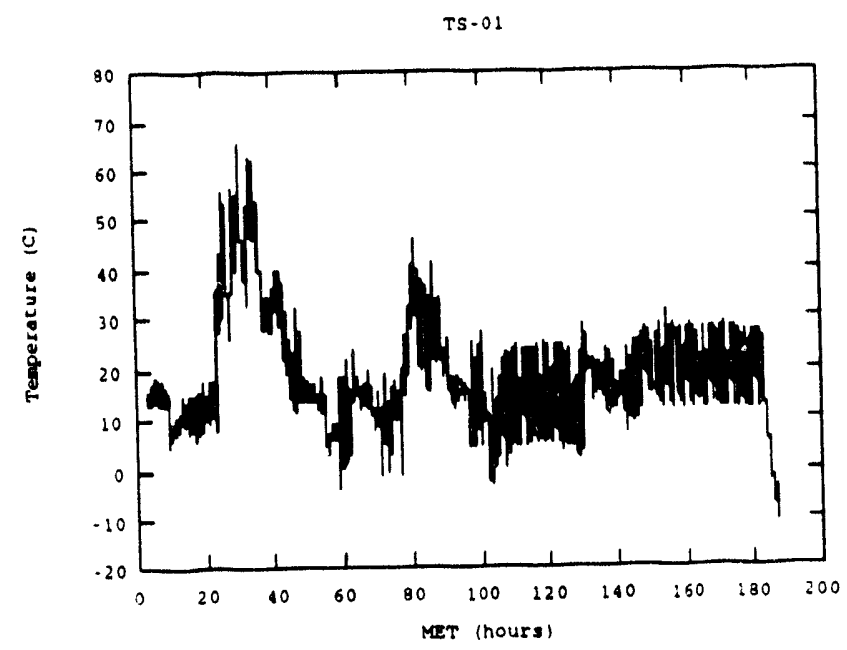

Figure 4.8 - Temperature recorded by the sensor on the Pallet 1 Static Stress Fixture (MSFC).

TS-02

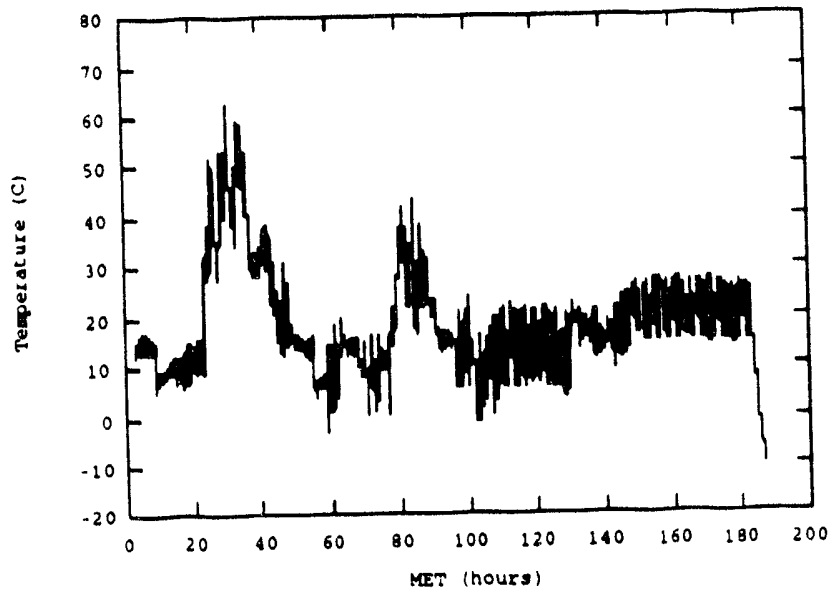

Figure 4.9 - Temperature recorded by the sensor on the Pallet 1 Composite Stress Fixture (JSC).

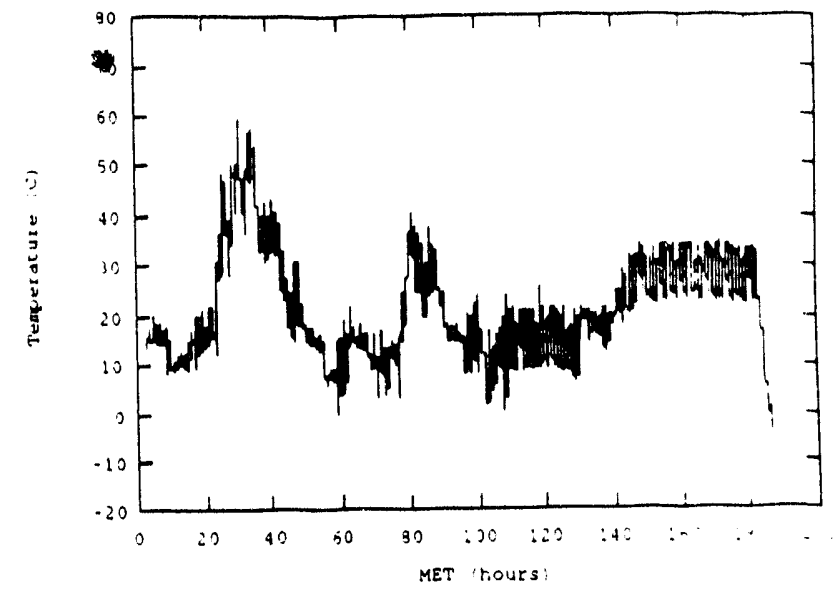

Figure 4.10 - Temperature recorded by the sensor on the Pallet 1 Scatterometer (Aerospace).

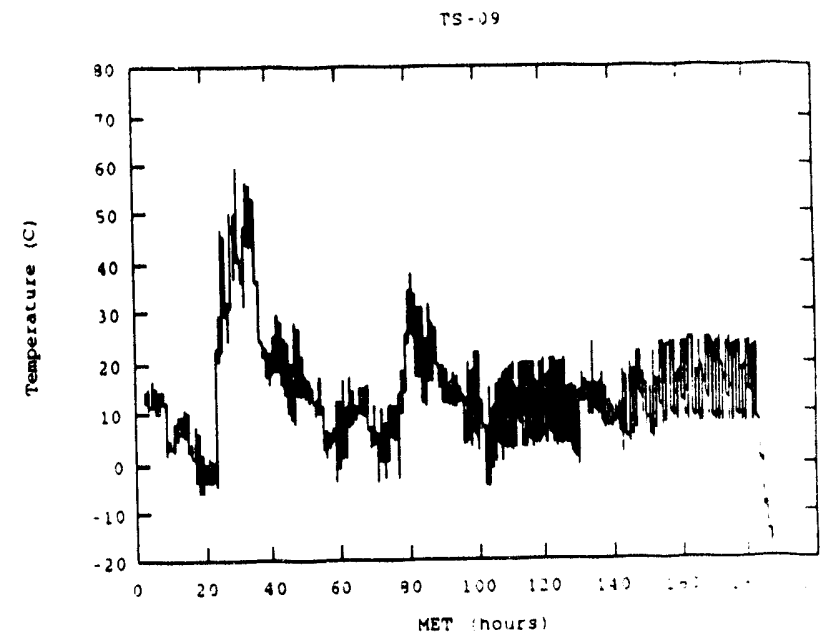

Figure 4.11 - Temperature recorded by the sensor on the Pallet 2 Composite Stress Fixture (LaRC.)

occurred when the heater was off near MET 151) hours) were 212.0, 210.2, 215.1 degrees Centigrade for the thermostat sensor and 183.7. 179.3, 191.7 degrees Centigrade for the sample cell sensor.

\section{SOLAR UVIVUV EXPOSURE}

An analytical determination of the equivalent Sun hours (the energy received by a surface with the Sun normally incident to it for 1 hour) experienced by the EOIM-III payload was performed in order to determine the solar ultraviolet and vacuum ultraviolet (UV/VUV) doses to exposed materials. EOIM-III operations consisted of only a few attitudes. Prior to EOIM-III operations, however, numerous 
attitudes were flown. Hence, two different methods were used to calculate the solar exposure.

The Thermal Interactive Mission Evaluation System (TIMES89)(ref. 7) computer program was used to characterize the solar exposure in the period prior to EOIM-III experiment operations. This program allows analysis of unshadowed sensing surfaces as they move and re-orient throughout their orbit. The solar irradiance on the experiment was calculated using the as-flown mission attitude timeline and the known orbit parameters. While all major attitudes were analyzed (both local vertical-local horizontal and inertially referenced, simplifying assumptions in the TIMES89 code prohibit modeling of attitudeto-attitude transitions. Thus, exposure during these periods was approximated by holding the previous attitude until halfway through the transition period and then instantaneously switching to the new attitude. The unshadowed sample surface assumption should hold reasonably well for this configuration as the Sun sensor was located high in the cargo bay and had few potential solar illumination blockers.

For the period of time encompassing EOIM-III operations, the cargo bay was facing into the velocity vector direction and the majority of the time was spent in either a biased tail-to-Earth or nose-to-Earth attitude. Since this period of time was of specific interest, a more detailed assessment of the potential blockage by orbiter components was performed. A detailed geometric model of the configuration was used and the location of the onset of solar blockage was assessed based on line-of-sight consicarations. using the Thermal Synthesizer System (TSS) sottware. (ref. 8) These data were used in conjunction with the following equation to determine the accumulated solar flux:

$$
F_{A C C}=S \cos \beta \int_{\alpha_{1}}^{\alpha_{2}}(-\sin \alpha d \alpha)=S \cos \beta[\cos \alpha]_{\alpha_{1}}^{\alpha_{2}}
$$

where... F FCC is the accumulated direct solar flux;

$$
\begin{array}{ll}
\mathrm{S} & \text { is the solar flux (assumed unity here, so that } \mathrm{F}_{\mathrm{ACC}} \text { is essentially a scaling } \\
\alpha_{1} & \text { is the terminator exit angle; } \\
\alpha_{2} & \text { is the orbit angle where blockage begins; } \\
\beta & \begin{array}{l}
\text { is the angle between the solar vector and the orbit plane (assumed constant } \\
\text { over a single orbit). }
\end{array}
\end{array}
$$

Note that this equation applies only to the case where the orbiter cargo bay faces into the velocity vector direction. Also, for all locations other than between the orbit angles $\alpha_{1}$ and $\alpha_{2}, F_{A C C}=($ ) due (1) blockage or angles greater than 90 degrees with respect to the solar vector.

If the accumulated direct solar flux is divided by the product of the solar constant and the orbit

Table 1 - Solar Uloraviolet Exposure History

\begin{tabular}{||c|c|c|c|c|c|c|}
\hline Mission & Sun & $250-200 \mathrm{~nm}$ & $200-150 \mathrm{~nm}$ & $150-119 \mathrm{~nm}$ & $121.5 \mathrm{~nm}$ & $119-10 \mathrm{~nm}$ \\
\hline Days & Hours & $\mathrm{mW} / \mathrm{cm}^{2}$ & $\mathrm{~mW} / \mathrm{cm}^{2}$ & $\mathrm{~mW} / \mathrm{cm}^{2}$ & $\mathrm{~mW} / \mathrm{cm}^{2}$ & $\mathrm{~mW} / \mathrm{cm}^{2}$ \\
\hline $0 \cdot 2.0$ & 5.8 & $2.00 \times 10^{-1}$ & $9.82 \times 10^{-3}$ & $1.10 \times 10^{-3}$ & $8.81 \times 10^{-4}$ & $3.4 \times 10^{-4}$ \\
\hline $2.0-4.0$ & 6.8 & $2.01 \times 10^{-1}$ & $9.85 \times 10^{-3}$ & $1.13 \times 10^{-3}$ & $9.10 \times 10^{-4}$ & $3.6 \times 10^{-4}$ \\
\hline $4.0-5.8$ & 10.4 & $2.01 \times 10^{-1}$ & $9.89 \times 10^{-3}$ & $1.16 \times 10^{-3}$ & $9.31 \times 10^{-4}$ & $3.7 \times 10^{-4}$ \\
\hline $5.8 \cdot 6.0^{+}$ & 0.5 & $2.02 \times 10^{-1}$ & $9.93 \times 10^{-3}$ & $1.17 \times 10^{-3}$ & $9.45 \times 10^{-4}$ & $3.7 \times 10^{-4}$ \\
\hline $6.0-7.0^{+}$ & 4.4 & $2.02 \times 10^{-1}$ & $9.95 \times 10^{-3}$ & $1.18 \times 10^{-3}$ & $9.51 \times 10^{-4}$ & $3.8 \times 10^{-4}$ \\
\hline $7.0-8.0^{\dagger}$ & 3.0 & $2.02 \times 10^{-1}$ & $9.99 \times 10^{-3}$ & $1.19 \times 10^{-3}$ & $9.63 \times 10^{-4}$ & $3.8 \times 10^{-4}$ \\
\hline & Hours & $\mathrm{J} / \mathrm{cm}^{2}$ & $\mathrm{~J} / \mathrm{cm}^{2}$ & $\mathrm{~J} / \mathrm{cm}^{2}$ & $\mathrm{~J} / \mathrm{cm}^{2}$ & $\mathrm{~J} / \mathrm{cm}^{2}$ \\
\hline Cumulative & 30.9 & 22.4 & 1.10 & .128 & .103 & .04 \\
\hline
\end{tabular}

* Mission-elapsed time in days. The numbers shown represent the beginning time and end time wi the measurement interval in days.

+ EOIM-III exposure period. 
period, the result is equivalent Sun hours. The solar exposure is calculated by multiplying the equivalent sun hours by the UV/VUV fluxes measured by the Solar-Stellar Comparison Experiment 1 (SOLSTICE)(ref. 9,10,11) on the Upper Atmosphere Research Satellite (UARS). The resulting solar exposure values are presented in table 1 . It should be noted that the short wavelength limit for SOLSTICE is $119 \mathrm{~nm}$, so the interval 119 to $10 \mathrm{~nm}$ are not measurements, but are from a model that uses the solar $10.7 \mathrm{~cm}$ radio flux. (ref. 12) Due to the shape of the solar spectrum, the $150-200 \mathrm{~nm}$ irradiance consists of about 80 percent from the $180-200 \mathrm{~nm}$ tlux, and the $119.150 \mathrm{~nm}$ irradiance consists of about 80 percent from the Lyman- $\alpha$ flux at $121.5 \mathrm{~nm}$. The $1-\sigma$ uncertainty for UARS measurements is 5 percent, and the $1-\sigma$ uncertainty for the extreme ultraviolet model results is 30 percent.

\section{ATOMIC OXYGEN FLUENCE}

The atomic oxygen fluence is determined in three different ways. First, the AOFLUX computer program (ref. 13), which incorporates the MSIS-86 atmospheric model and the as-flown Space Shuttle trajectory was used to calculate oxygen atom fluence. Second, the oxygen atom fluence was measured directly from Kapton film erosion, as corrected for configuration interactions produced by the sample holder. The Kapton film erosion measurements are discussed in detail in reference 6. Finally, ambient oxygen atom measurements were made using a mass spectrometer that was calibrated before and after the mission in the High Velocity O-atom Beam (HVAB) system at the Los Alamos National Laboratory (LANL). (ref. 14) All fluence estimates are summarized in table 3.

\section{AOFLUX Calculations}

The AOFLUX program(ref. 13), written to calculate the expected O-atom fluence, was based on the MSIS-86 atmospheric model(ref. 2,3) and the as-flown timeline, which included the altitude. latitude and longitude. Solar activity parameters recorded during STS-46 at the Space Environment Services Center (National Oceanic and Atmospheric Administration) were used to account for the magnetic substorm activity observed during EOIM-III. Mission-specific values for the daily-average $A_{p}$ geomagnetic activity and the daily solar F10.7 values are given in table 2. (ref. 15)

The O-atom densities calculated from MSIS-86 were used with the velocity of the spacecraft to calculate the total flux to the spacecraft. Integrating the total flux throughout the mission gives a total fluence to the spacecraft (before orientation effects are included) of $3.4 \times 10^{20} \mathrm{O}$-atoms $/ \mathrm{cm}^{2}$. The total flux at each time increment was multiplied by the cosine of the ram angle (shown in figure 2) to obtain the net flux to the EOIM-III payload (shown in figure 5). Note that the fluxes for angles greater than $9($ ) degrees were simply set to zero. By integrating the net flux throughout the mission, the fluence to the EOIM-III payload is calculated to be $2.3 \times 10^{20} \mathrm{O}$-atoms $/ \mathrm{cm}^{2}$ (see table 3 ). Ninety-five percent of this net fluence occurs during the low-altitude ram orientation, as can be seen in figure 5 .

\section{Kapton Recession Measurements}

Measurements of Kapton polyimide surface recession or weight loss made following several previous Low Earth Orbit (LEO) flight experiments (ref. 4,16,17) have produced the widely accepted value of the Kapton reaction efficiency of $3.0 \pm 0.3 \times 10^{-24} \mathrm{~cm}^{3} /$ atom. MSIS-86 was used to calculate the $\mathrm{O}$-atom fluence needed to calculate polymer reaction efficiencies in all previous LEO flight experiments. In order to determine the EOIM-III O-atcm fluence using Kapton surface recession or weight loss measurements, without referring indirectly to MSIS-86 calculations, an
Table 2 - Daily-Average $A_{p}$ Geomagnetic Activity Values and the Daily Solar F10.7 Microwave Flux Values Used in the AOFLUX/MSIS-86 Calculations ${ }^{\text {(ref. 15) }}$

\begin{tabular}{|c|c|c|c|}
\hline Date & $\begin{array}{c}\text { Daily } \\
\text { An }\end{array}$ & $\begin{array}{l}\text { Daily } \\
\text { F10.7 } \\
\end{array}$ & $\begin{array}{c}90 \text { day average } \\
\text { F10.7 }\end{array}$ \\
\hline $07 / 31 / 1992$ & 11 & 103.0 & 1250 \\
\hline $08 / 01 / 1992$ & 09 & 110.0 & 125.0 \\
\hline $08 / 02 / 1992$ & 06 & 125.0 & 124.0 \\
\hline $08 / 03 / 1992$ & 05 & 131.0 & 124.0 \\
\hline $08 / 04 / 1992$ & 13 & 131.0 & 124.0 \\
\hline $08 / 05 / 1992$ & 43 & 131.0 & 124.0 \\
\hline $08 / 06 / 1992$ & 19 & 138.0 & 124.0 \\
\hline $08 / 07 / 1992$ & 42 & 141.0 & 125.0 \\
\hline $08 / 08 / 1992$ & 22 & 144.0 & 1250 \\
\hline
\end{tabular}




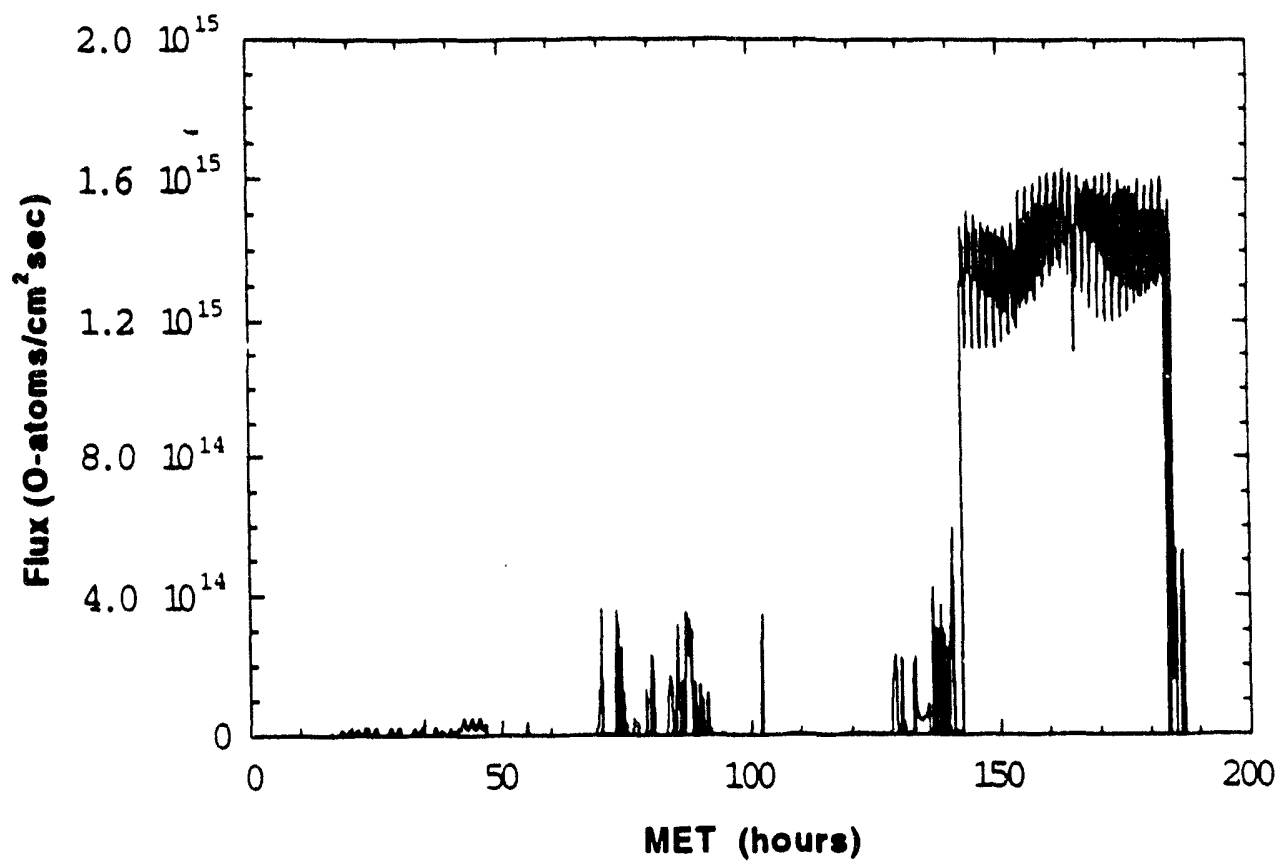

Figure 5 - Atomic oxygen flux on the EOIM-III payload during STS-46, as calculated using the MSIS-86 atmospheric model with daily average $A_{p}$ and F10.7 values. Note the magnitude of the diurnal variations during the ram period between hours 142 and 185.

independent measurement of Kapton reaction efficiency was cuisusted in the HVAB at LANL as described in reference 6. The EOIM-III O-atom fluence based on the LANL measurement of the Kapton polyimide reaction efficiency is $2.3 \pm 0.07 \times 10^{20}$ atoms $/ \mathrm{cm}^{2}$ based on weight loss and $2.4 \pm 0.09 \times 10^{20} \mathrm{O}$ atoms $/ \mathrm{cm}^{2}$ based on surface recession measured by profilometry. The various 0 -atom tluence determinations for EOIM-III are summarized in table 3 where it can be seen that MSIS- 86 calculations. mass spectrometer measurements and Kapton weight loss or profilometry measurements produce neirly identical fluence determinations.

\section{Mass Spectrometer Measurements}

The EOIM-III quadrupole ion/neutral mass spectrometer(ref. 18) scanned a mass to charge ratio range of 0 to 72 amu/unit charge every 5.12 seconds with a digital resolution of $0.142 \mathrm{M} / \mathrm{e} / \mathrm{channel}(512$ digital data channels corresponding to 0-72 amw/unit charge). The mass spectrometer resolution $(\Delta \mathrm{M} / \mathrm{M})$ calculated as mass peak width (full width at half maximum) at mass 28 was .011 throughout the mission and during the pre and post flight calibrations. The mass spectrometer output signal was logarithmically amplified, which permitted the display of seven orders of magnitude in mass spectrometer detector current in a 0 to 5 volt analog signal, which was digitized with an 8-bit analog-todigital converter. Mass spectra were produced in either ion or neutral operating mode. In neutral mode. a repeller grid excluded naturally occurring ionospheric ions and neutral gaseous species entering the ion source were ionized by electron impact. In ion mode, the repeller grid and the filaments producing electrons for electron impact ionization were shut off and naturally occurring ionospheric ions entering the ion source volume were mass analyzed and detected.

Approximately 46,000 mass spectra were recorded during STS-46. Prior to the beginning of EOIM-III operations, the mass spectrometer operated in the ion and neutral mode in alternating one minute time periods. During EOIM-III operations, ion and neutral mass spectra were recorded according to a predetermined sequence which also involved periodic observation of the gaseous and plasma environments in the various carousel sectors. For a comparison of mass spectrometer to MSIS-86 data, it is useful to calculate the MSIS-86 fluence during the time that the mass spectrometer was on tilted up, and measuring neutral species. The on-time MSIS-86 fluence is $1.1 \times 10^{20} \mathrm{O}$-atoms $/ \mathrm{cm}^{2}$, or 48 percent of the net MSIS-calculated fluence. 
The primary objective of the EOIM-III mass spectrometer experiment was to measure the $\mathrm{O}$ atom fluence for comparison with the fluence calculated using the MSIS-86 model of the thermosphere. The mass spectrometer was subjected to an extensive calibration process both before and after the flight(ref. 14) to permit accurate quantitative estimates of $\mathrm{O}$-atom flux and fluence from the mass spectrometer data. The $\mathrm{O}$ atom fluence was determined from the mass spectrometer data as follows. First, the mass spectrometer data were divided into 5-minute intervals corresponding to the 5-minute intervals used in the MSIS-86 calculations. Within each 5minute interval, all complete, valid spectra appropriate for use in neutral flux and fluence calculations were averaged. Figure 6 shows a typical 5-minute-average spectrum taken early in

the EOIM-III ram exposure period. Figure 7 shows an overview of the 5 -minute-average spectra taken throughout STS-46. In figure 7, an additional averaging of 12 adjacent 5-minute-average spectra was included to reduce the line density of the plot.

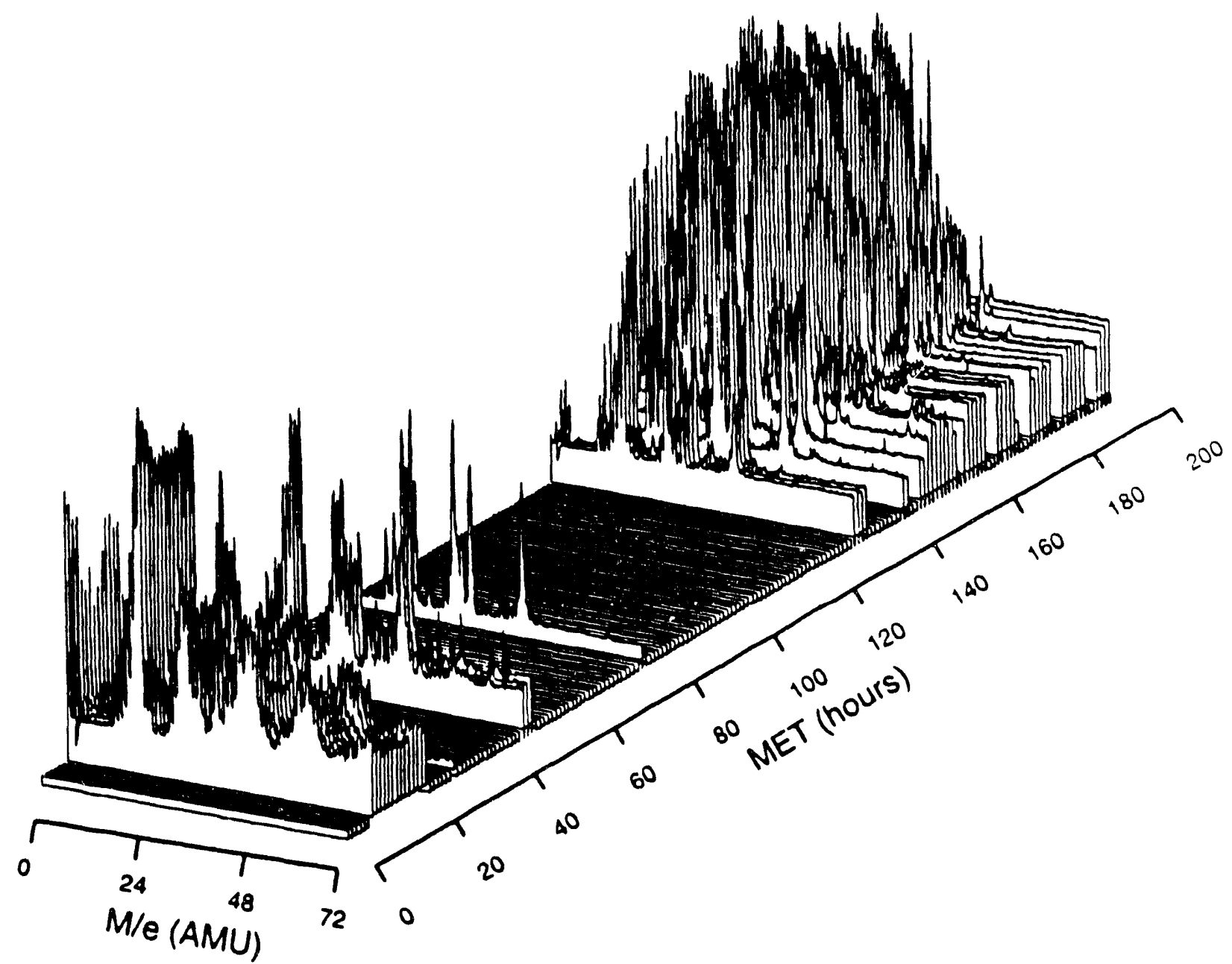

Figure 7 - Neutral spectra from the EODM-III mass spectrometer. The data have been averaged into l-hour time blocks firr a qualitative view of the entire STS $\mathbf{4 6}$ mission. The start of the mission is towards the front of the picture, and that linc? indicate the times when the mass spectrometer was either turned off, facing the carousel. or in ion mode 
The 5-minute-average spectra were used to calculate $\mathrm{O}$-atom fluence. Mass peak areas (peak. sums), not peak heights were used throughout in order to obtain the best possible signal to noise ratio. Peak sums, which retained the units of Amperes, were calculated by summing the mass spectrometer signal amplitude in the seven adjacent digital data channels containing a mass peak. The unmodified peak sums for the $\mathrm{M} / \mathrm{e}=$ 16,28 , and 32 peaks $\left(\mathrm{O}, \mathrm{N}_{2}\right.$, and $\left.\mathrm{O}_{2}\right)$ are shown in figures 8 through 10 . To calculate the $\mathrm{O}$-atom flux, the peak sum at $\mathrm{M} / \mathrm{e}=16$ was corrected for contributions fiom M/e $=16$ fragment ions from molecular oxygen and water by subtracting 26 percent of the $\mathrm{M} / \mathrm{e}=32\left(\mathrm{O}_{2}\right)$ peak sum and 1.7 percent of the $\mathrm{M} / \mathrm{e}=18\left(\mathrm{H}_{2} \mathrm{O}\right)$ peak sum, as shown in figure 12 . The $\mathrm{O}$-atom flux that produced each 5-minute-average spectrum was then calculated by multiplying the corrected $\mathrm{M} / \mathrm{e}=16$ peak sum by a calibration function described below. The O-atom fluence, was then determined by adding up the fluences for the various 5-minute periods.

The calibration function was derived from both ground based calibration of the mass spectrometer in the HVAB at LANL and mass spectrometer performance data from STS-46 itself. The EOIM-III mass spectrometer showed an $\mathrm{O}$-atom fluence dependent sensitivity decay both in the HVAB at LANL and during STS- 46. However, different sensitivity decay functions were observed in the lab and on orbit as shown in figure 11. For this reason, the zero-fluence $\mathrm{O}$ atom flux calibration factor determined in the HVAB at LANL was used with an empirical sensitivity decay function derived from a fit to the corrected $\mathrm{M} / \mathrm{e}=16$ peak sum data from STS -46 to produce the calibration function:

$$
y=\frac{0.006}{0.0047968-0.0022472 * \log (\text { MET }-142.5)}
$$

Using this calibration function, the corrected $\mathrm{O}$-atom peak sums, and the percentage of mass spectrometer on-time, the measured EOIM-III mission fluence is $2.3 \pm 0.7 \times 10^{20} \mathrm{O}$-atoms $/ \mathrm{cm}^{2}$.

The EOIM-III mass spectrometer was calibrated for direct measurement of high velocity $\mathrm{O}$-atom flux both before and after flight on STS-46 in the HVAB at LANL. Details of the calibration methodology, and a summary of calibration methods and results have been reported previously. (ref. 14) Calibration studies were conducted over a period of several years

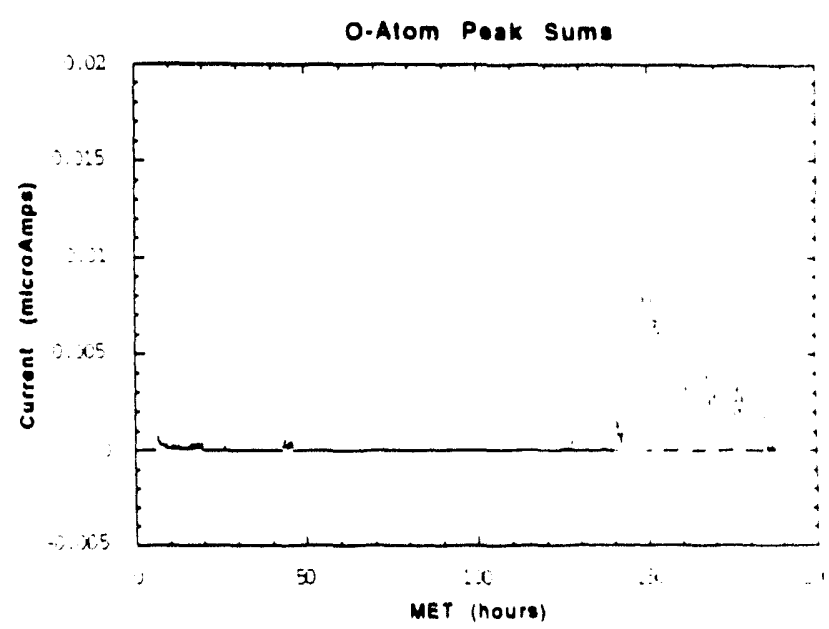

Figure 8 - $\mathrm{O}$-atom (e/M=16) current measured hy the mass spectrometer.

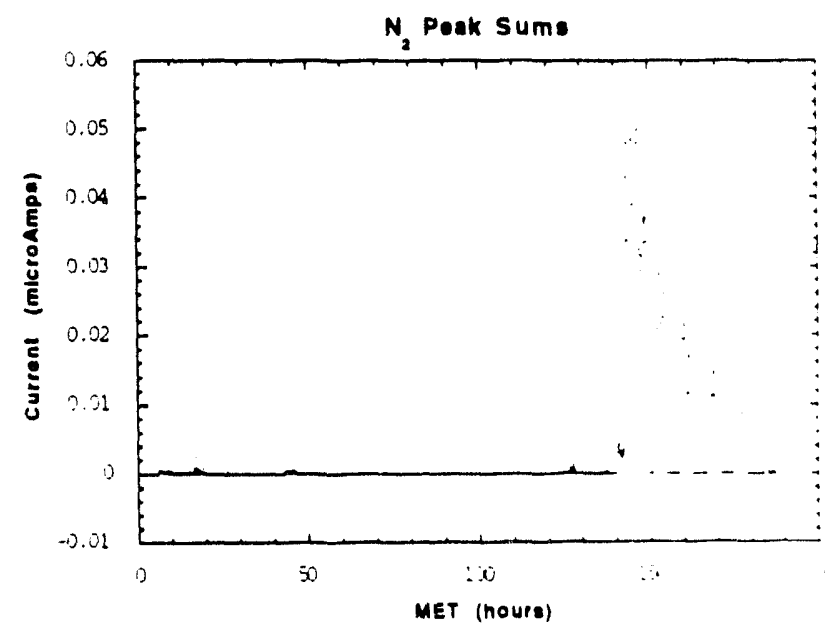

Figure $9-\mathrm{N}_{2}(\mathrm{e} / \mathrm{M}=28)$ current measured by the mass spectrometer.

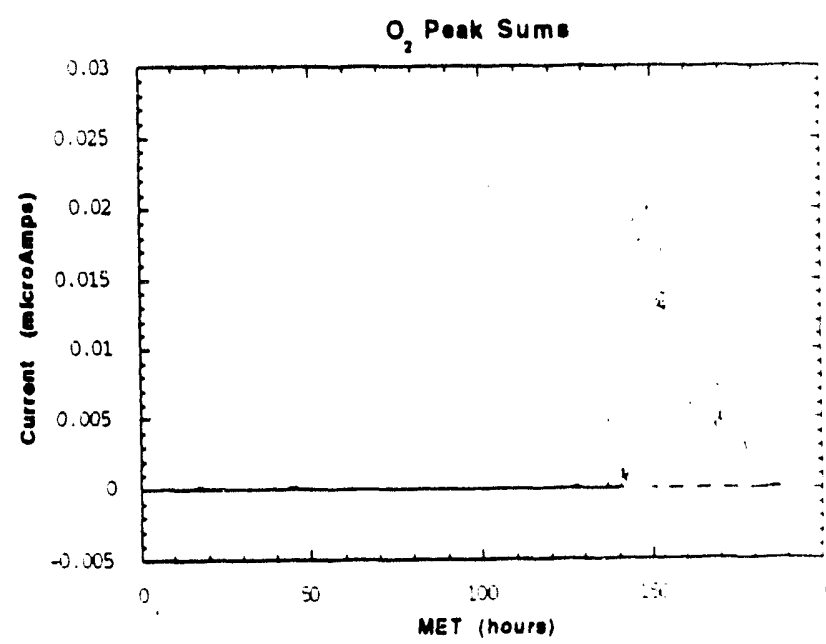

Figure $10-\mathrm{O}_{2}(\mathrm{e} / \mathrm{M}=32)$ current measured by the mass spectrometer. 
EOIMnANL Comparison

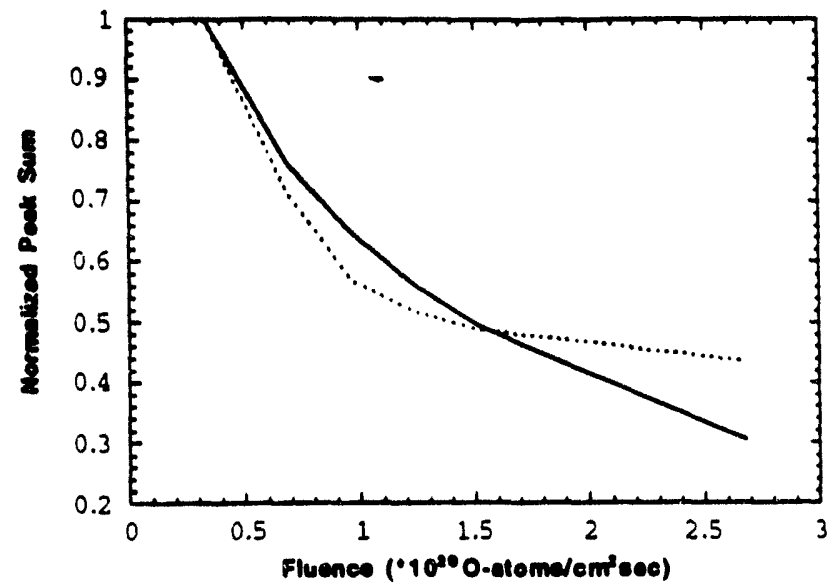

Figure 11- Comparison of O-atom peak decay during flight and laboratory exposure.

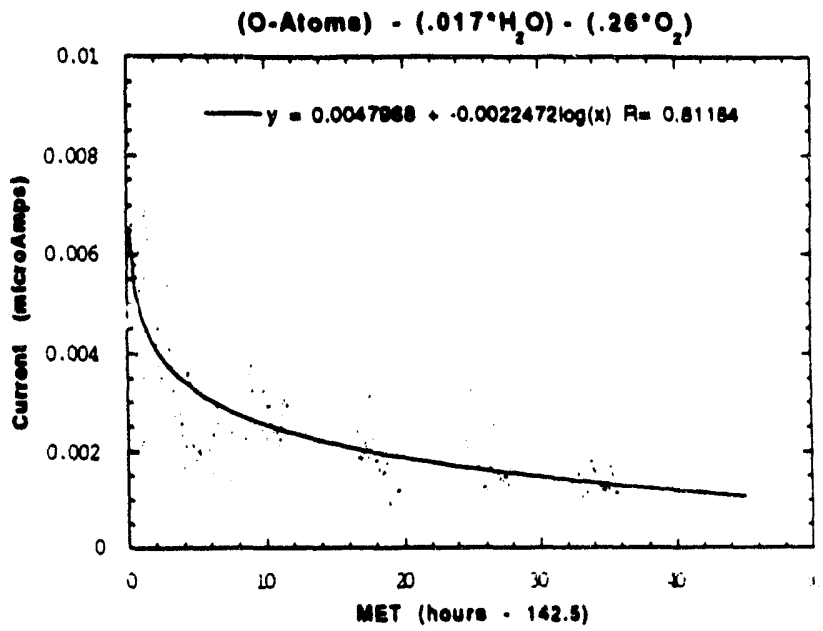

Figure 12 - Logarithmic fit to the corrected O-atom peak as a function of MET after 142.5 bours.

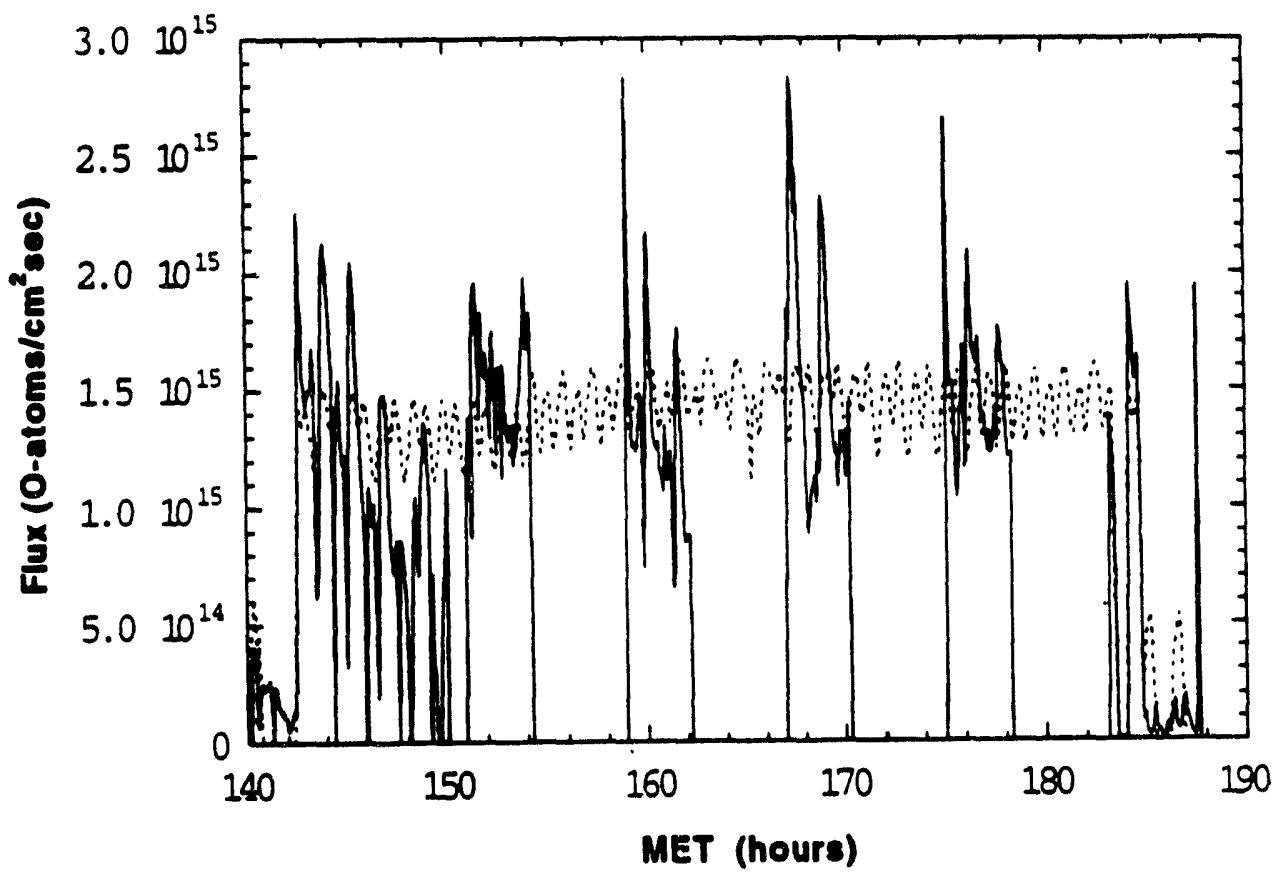

Figure 13 - Atomic oxygen flux calculated using the empirical fit to the O-atom peak (solid line).

For comparison, the MSIS-86 flux is shown (dashed line).

prior to STS-46 as well as after the mission. In general the EOIM-III mass spectrometer showed excellent stability with the O-atom flux at low O-atom fluence, showing a maximum variation of 5 percent and the partial pressure sensitivity for nitrogen gas varying by less than 10 percent. Some changes in the fragmentation yield of $\mathrm{O}_{2}{ }^{+}$were, however, observed so that the 10 percent correction factor reported in reference 14 was increaser to 26 percent for 0 -atom fluence calculations as a result of thermal gas calibration measurements conducted prior to and just after STS-46.

\section{EOM-III CONTAMINATION}

Since atomic oxygen effects are affected by contamination, deposits on sample surfaces were measured both in flight and post flight. In flight measurements were made using quartz $\mathrm{cr}, \mathrm{sial}$ microbalances (QCMs) in the Environment Monitor Package (EMP) provided by Goddard Spaceilight Center. (ref. 19) The EMP contained five QCMs - four coated with reactive materials and one not 
Table 3 - Summary of EOIM-III Atomic Oxygen Fluence Estimates

\begin{tabular}{|l|c|c|}
\hline \begin{tabular}{l} 
Measurement Method \\
\hline AOFLUX (MSIS-86) calculation
\end{tabular} & Fluence & Measurement Uncertainty \\
\hline Kapton Erosion Weight Loss (3 Samples) & $\begin{array}{c}2.3 \times 10^{20} \\
\pm 0.35 \times 10^{20} \\
(15 \% \text { estimated from MSIS) }\end{array}$ \\
\hline $\begin{array}{l} \pm 0.07 \times 10^{20} \\
\text { (weight loss uncerainty) }\end{array}$ \\
\hline $\begin{array}{c} \pm 0.09 \times 10^{20} \\
\text { (profilometry uncertainty) }\end{array}$ \\
\hline $\begin{array}{l}\text { Mass Spectrometer - Empirical Calibration from In- } \\
\text { Flight Data }\end{array}$ & $2.34 \times 10^{20}$ & (TBD) \\
\hline
\end{tabular}

overcoated - and was located to the side of pallet one as shown on the right in figure 3. Response from the uncoated crystal for the entire mission is shown in figure 14 and is representative of the response of all five microbalances. A large amount of contamination ( several thousand Angstroms) is indicated and most of the deposition occurs during the EOIM-III portion of flight.

Because of the inconsistency of these results with the numerous post flight XPS surface analyses which show only small amounts of contamination on the top plates of the experiment, it is expected that the EMP was contaminated from a source below the pallet top, but within the EOIM-III hardware.

The results of the post flight contamination survey of the EOIM-III payload are shown in table 4. X-ray photoelectron spectroscopy

(XPS) was used to provide measurements of the elemental composition and state of chemical combination of the near-surface region (10-50 Angstroms from the surface) of the sample. Samples were surveyed for a variety of elements but only silicon was identified as different from the substrate composition and is reported in table 4. For all the surfaces measured, the substrate elements were evident in the XPS spectra indicating that the contaminant layer was less than 20 Angstroms. It can be concluded from the XPS results that a small amount of contamination did deposit on the experiment top pallets but is insignificant and should not affect the atomic oxygen measurements.

Additional evidence confirming the relatively low levels of contamination occurring on EOIM-III samples are the measured reaction efficiencies of Kapton and other polymer films which were in good agreement with measurements made on STS-8 and STS-41 and LDEF, as well as the performance of the atomic oxygen monitors (AOMs) provided by Marshall Space Flight Center. (ref. 20) The AOM consisted of an array of thin film carbon resistors which showed increasing resistance as the carbon is removed by $\mathrm{O}$-atom reaction. The AOMs showed a constant or slightly increasing rate of resistance change throughout the EOIM-III ram period which would not be observed if a coating of $\mathrm{SiO}_{2}$ were accumulating on the carbon resistor surfaces at the rates indicated by the EMP.

\section{SUMMARY AND CONCLUSIONS}

A detailed characterization of the EOIM-III materials exposure environment has been completed. The atomic oxygen fluence calculated using the MSIS-86 model of the thermosphere and as-tlown 
Table 4 - EOMM-III X-ray Photoelectron Spectroscopy contamination survey

\begin{tabular}{|c|c|c|}
\hline PAYLOADLOCATION & SAMPLE TYPE & ATOM \% Si \\
\hline mass sioc. ram & Silver/Teflon & 4.4 \\
\hline mass spec. payload bay view & Silver/Tenton & 12.2 \\
\hline mass snec. starboard & Silver/Teflon & 0.0 \\
\hline mass spec. ram & Kapton tape (exposed) & 3.2 \\
\hline mass spec. ram & Kapton tape (unexposed) & 0.0 \\
\hline VET mount & steel washer (exposed) & 2.7 \\
\hline SUV mount & steel washer (exposed) & 0.0 \\
\hline \multirow[t]{6}{*}{$60^{\circ} \mathrm{C}$ tray } & steel ground strap & 3.8 \\
\hline & polysulfone (exposed) & 0.8 \\
\hline & polysulfone (unexposed) & 0.0 \\
\hline & Mylar-A (exposed) & 2.4 \\
\hline & Mylar-A (unexposed) & 0.0 \\
\hline & aluminum & 7.1 \\
\hline \multirow[t]{5}{*}{$120^{\circ} \mathrm{C}$ tray } & steel washer & 7.7 \\
\hline & Kanton (exposed) & 2.0 \\
\hline & Kapton (unexposed) & 0.0 \\
\hline & aluminum & 9.4 \\
\hline & aluminum & 6.6 \\
\hline passive tray $7 \& 8$ & 7 polymer films & $3.8 \pm 2.6$ \\
\hline
\end{tabular}

Space Shuttle trajectory data (combined with the daily measurements of the solar activity and geomagnetic indices) is in good agreement with mass spectrometer and O-atom dosimeter measurements made during STS-46. Temperature measurements made during EOIM-III provide a complete thermal history of the payload and provide the investigators with useful sample temperature histories. UARS investigators provided solar UV and VUV measurements which, combined with the STS-46 trajectory and vehicle attitude data, allow calculation of net solar UV and VUV radiation doses to the EOIM-III materials samples. Post flight XPS analysis of materials samples as well as in-flight performance of the AOM both demonstrate that contamination of EOIM-III was, in fact, nominal and in no way intertered with the scientific and programmatic objectives of the payload. The severe contamination indicated by the TQCM sensors in the EMP component of EOIM-III was a localized in the immediate vicinity of the EMP.

The detailed characterization of LEO exposure conditions during STS-46 reported above, provides the investigator community with the necessary foundation for a complete interpretation of the effects of the LEO space environment on the materials and instruments flown on EOIM-III.

\section{REFERENCES}

1. J. T. Visentine, and L. J. Leger, "Material Interaction with the Low Earth Orbital Environment: Accurate Reaction Rate Measurements," in Proceedings of the NASA Workshop on Atomic Oxygen Efiects, Nov. 10-11, 1986, D. E. Brinza, Ed., JPL Publication 84-14, pp. 11-20, June 1. 1987.

2. A. E. Heddin, MSIS-86 Thermospheric Model, Journal of Geophys. Res., vol.92, No. A5, pp. 4649-4662, May 1, 1987.'

3. A. E. Heddin, High Altitude Atmospheric Modeling, NASA Technical Memorandum 100707. October 1988. 
4. J. T. Visentine, L. J. Leger, J. F. Kuminecz, I. K. Spiker, "STS-8 Atomic Oxygen Effects Experiment", AIAA paper AIAA-85-0415, 23rd Aerospace Sciences Meeting, Reno, Nevada, Jan. 14-17, 1985.

5. J. T. Visentine, L. J. Leger, "Materials Interactions with the Low-Earth Orbital Environment: Accurate Reaction Rate Measurements", AIAA paper AIAA-85-7019, AIAA Shuttle Environments and Operations II Conference, p 168, Nov. 1985.

6. Lubert Leger, Steve Koontz, Jim Visentine, Don Hunton, Jon Cross, Charles Hakes, "An Overview of the Evaluation of Oxygen Interactions with Materials III Experiment: Space Shuttle Mission 46: July-August, 1992." Third LDEF Post-Retrieval Symposium, Williamsburg, Virginia, Nov. 1993.

7. S. L. Rickman, C. R. Ortiz, Thermal Interactive Mission Evaluation System (TIMES89), NASA publication JSC-23852, Sept. 1989.

8. Thermal Synthesizer System (TSS) Users Manual, LMSC/F191409, developed under contract NAS 9-17923, Dec. 1992.

9. Gary Rottman and Tom Woods, High Altitude Observatory, National Center for Atmospheric Research, private communication to Steve Koontz.

10. Gary J. Rottman, Thomas N. Woods, Thomas P. Sparn, Solar-Stellar Irradiance Comparison Experiment 1: 1. Instrument Design and Operation, J. Geophys. Res., vol. 98, no. D6, p. 10667. June 20, 1993.

11. Thomas N. Woods, Gary J. Rottman, Gregory J. Ucker, Solar-Stellar Irradiance Comparison Experiment 1: 2. Instrument Calibrations, J. Geophys. Res., vol. 98, no. D6, p. 10679, June 20, 1993.

12. Hans E. Hinteregger, Katsura Fukui, Observational, Reference and Model Data on Solar EUV. from Measurements on AE-E, Geophys. Res. Let., vol. 8, no. 11, p.1147, Nov. 1981.

13. Charles L. Hakes, David T. Bui, AOFLUX program, Lockheed Engineering \& Sciences Company. developed under contract NAS 9-17900, 1993.

14. S. L. Koontz, J. B. Cross, D. Hunton, E. Lan, "Characterization and Calibration of the EOIM-III Flight Mass Spectrometer in a High Velocity Oxygen Atom Beam", Materials Degradation in Low Earth Orbit (LEO), V. Srinivasan and B. A. Banks, Ed., The Minerals, Metals \& Materials Sociely, 1990.

15. Space Environment Services Center, (Mission-specific values for the daily-average $A_{p}$ geomagnetic activity and the daily solar F10.7 values), private communication to Steve Koontz.

16. D. G. Zimcik, C. R. Magg, "Results of Apparent Oxygen Reactions with Spacecraft Materials During Shuttle Flight STS-41-G," J. Spacecraft, vol. 25, no. 2, March-April 1988.

17. S. Koontz, G. King, A. Dunnet, T. Kirkendahl, R. Linton, J. Vaughn, "The ISAC Atomic Oxygen Flight Experiment," J. Spacecraft, in press, 1994.

18. D. E. Hunton, E. Trzcinski, L. Wlodyka, G. Federico, and J. Dorian, "Quadrupole Ion/Neutral Mass Spectrometer (for Space Shuttle Applications)", AFGL-TR-86-0084, Air Force Geophysics Laboratory, Hanscomb Air Force Base, MA, April 7, 1987.

19. P. Chen and S. A. Straka, Goddard Space Flight Center, private communication to Steve Koontz.

20. R. C. Linton, J. A. Vaughn, M. M. Fincknor, R. R. Kamenetzky, R. F. DeHaye,A. F. Whitaker, "Orbital Atomic Oxygen Effects on Materials: An Overview of MSFC Experiments on the STS +46 EOIM-3," AIAA paper AIAA-93-4102, AIAA Space Programs and Technologies Conference and Exhibit, Huntsville, AL, Sept. 21-23, 1993. 
11
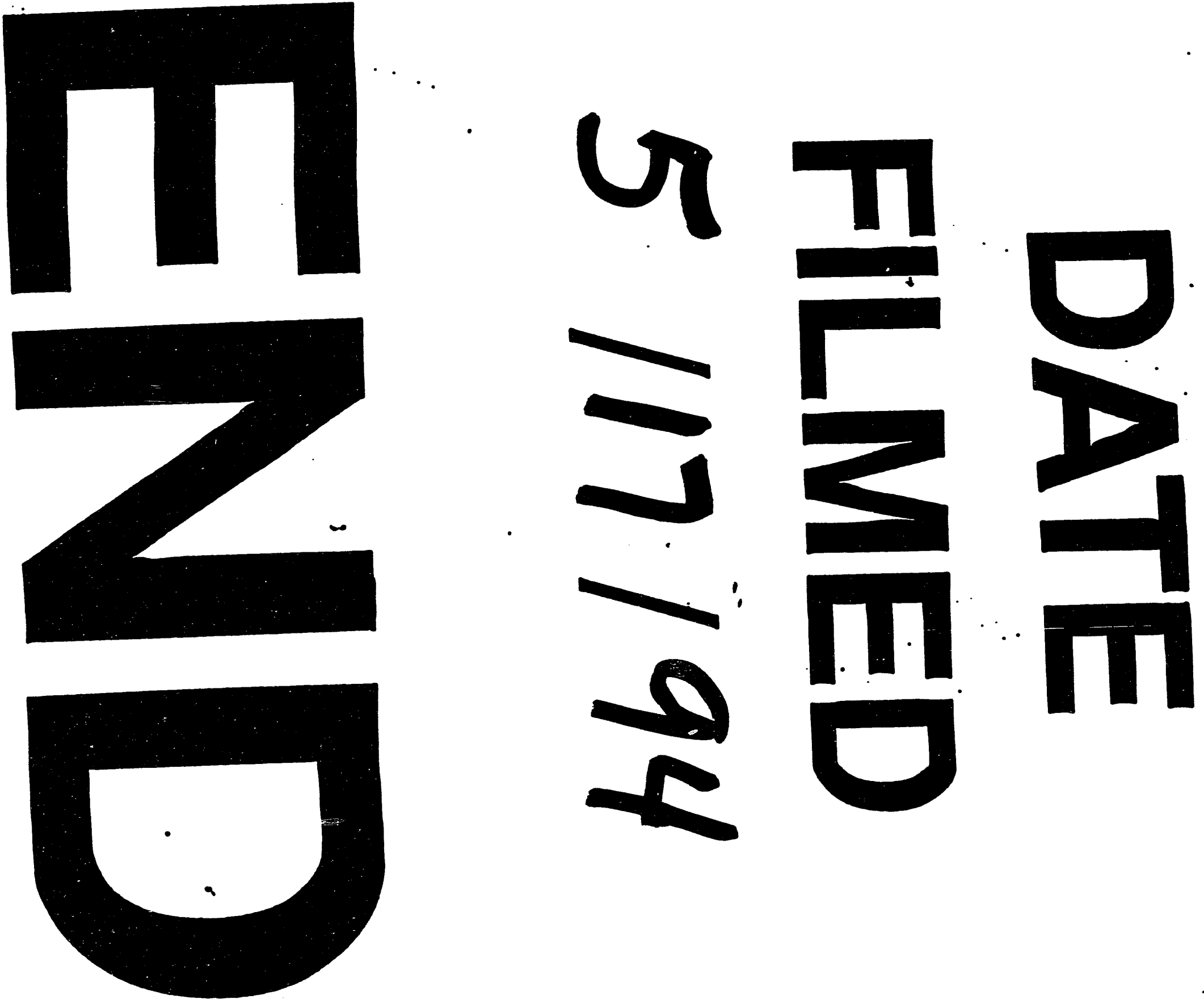


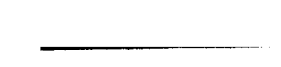

